\title{
LONGSHORE SEDIMENT TRANSPORT ALONG THE BELGIAN COAST
}

\author{
TOON VERWAEST, ROSALIA DELGADO, JOB JANSSENS, JOHAN REYNS
}

Flanders Hydraulics Research, Berchemlei 115, 2140 Antwerp, Belgium. toon.verwaest@mow.vlaanderen.be.

\begin{abstract}
The littoral drift along the Belgian coast is strongly influenced by the presence of different types of structures but the mechanisms driving these effects are not yet fully understood. In addition, beach and foreshore nourishments are frequently performed and dredging and dumping is a constant activity to guarantee safe navigation. Due to all these factors and to the lack of field data, it is difficult to make an accurate and reliable assessment of the net longshore transport in the area. A morphological trend analysis based on ten years of topo-bathymetric data is carried out in order to make a first estimation of net transport along the Belgian coast. Results are compared to those obtained from 1D numerical modeling of the longshore transport. In this paper, results from both studies are presented and discussed.
\end{abstract}

\section{Introduction}

The Belgian coast, located along the Southern Bight of the North Sea, is a $67 \mathrm{~km}$ strip of sandy beaches bordered by the Scheldt estuary at its northernmost end. This area is highly urbanized and protected by numerous coastal structures placed along most of the coast. Beach nourishments are permanently needed at several locations and due to the shallow continental shelf and intensive navigation and shipping activity in the area, northeast of the English Channel, dredging and dumping is regularly carried out.

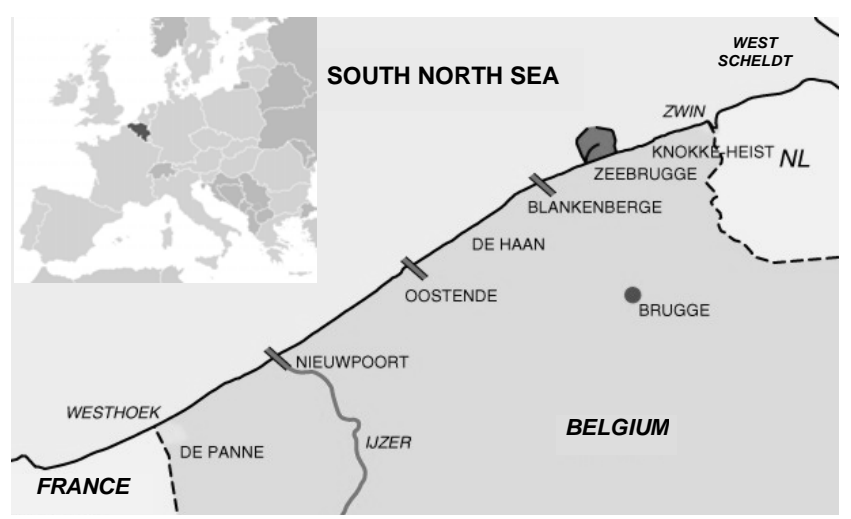

Fig. 1. Location of the study area, the Belgian coast, including main harbors. A major feature is the harbor of Zeebrugge. 
One of the Belgian coast main manmade features is the Harbor of Zeebrugge. This harbor was extended in 1986 with breakwaters, having a length exceeding $3 \mathrm{~km}$, that strongly interfere with the littoral drift in the area. One of the consequences is a relatively fast accumulation of sediment upstream the harbor, in the Blankenberge area.

Different multidisciplinary research projects are carried out in order to develop tools and obtain reliable information about sediment dynamics in the area. One of the goals is the evaluation of the net longshore transport. These studies include the analysis of historical morphological evolution of the coastline and 1D and 2D numerical modeling. Results from both, morphological trend analysis and numerical modeling are presented and compared in this paper.

\section{Configuration and dynamics in the study area}

The study area is a quasi-uniform sandy coast characterized by a rather gentle slope and a semidiurnal mean tidal range of about $4 \mathrm{~m}$. The residual tidal current component is oriented to the northeast. The same dominant direction is found for the littoral drift.

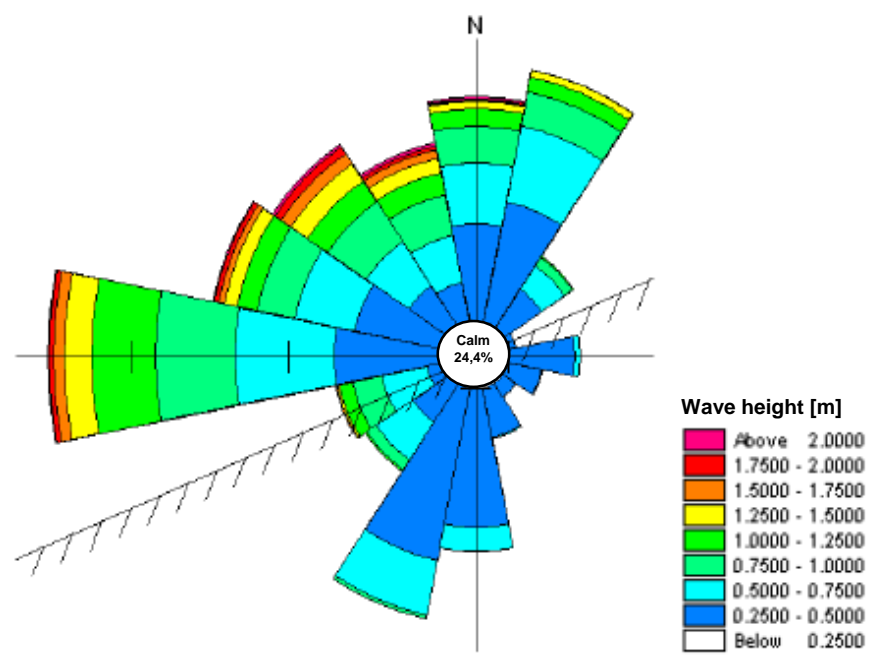

Fig. 2. Wave height Hrms in function of wave direction in the Blankenberge area at $-10 \mathrm{~m}$ TAW1 for the period 10/01/2000 to 31/08/2005.

\footnotetext{
${ }^{1}$ Local reference system used in Belgium, equivalent to MLLWS at Ostend.
} 
Figure 2 summarizes the wave climate at the coast west of the harbor of Zeebrugge. The figure shows the dominant wave direction and the most frequent ranges of significant wave heights. Most of the waves arrive from the North and West quadrants.

The bathymetry is rather uniform, as shown in Figure 3, with a relatively constant slope at the foreshore where isobaths are mostly parallel to the coastline. Sediments in the area are mainly composed of sandy deposits, with locally important mud accumulations.

\section{Methodology for the identification of morphological trends: updrift accumulation Southwest of Zeebrugge}

A GIS morphological analysis based on yearly topographic and bathymetric measurements spanning a 10 year period was carried out in the area between Blankenberge and the westernmost breakwater of Zeebrugge. Part of the total longshore transported sediment accumulates in the navigation channel of Blankenberge harbor which is permanently dredged to avoid infilling. The material dredged in this area is used either for nourishments in the area or disposed off at a close location offshore. The rest of the transport associated to the littoral drift is assumed to be blocked by the harbor of Zeebrugge and, therefore, kept in the area.

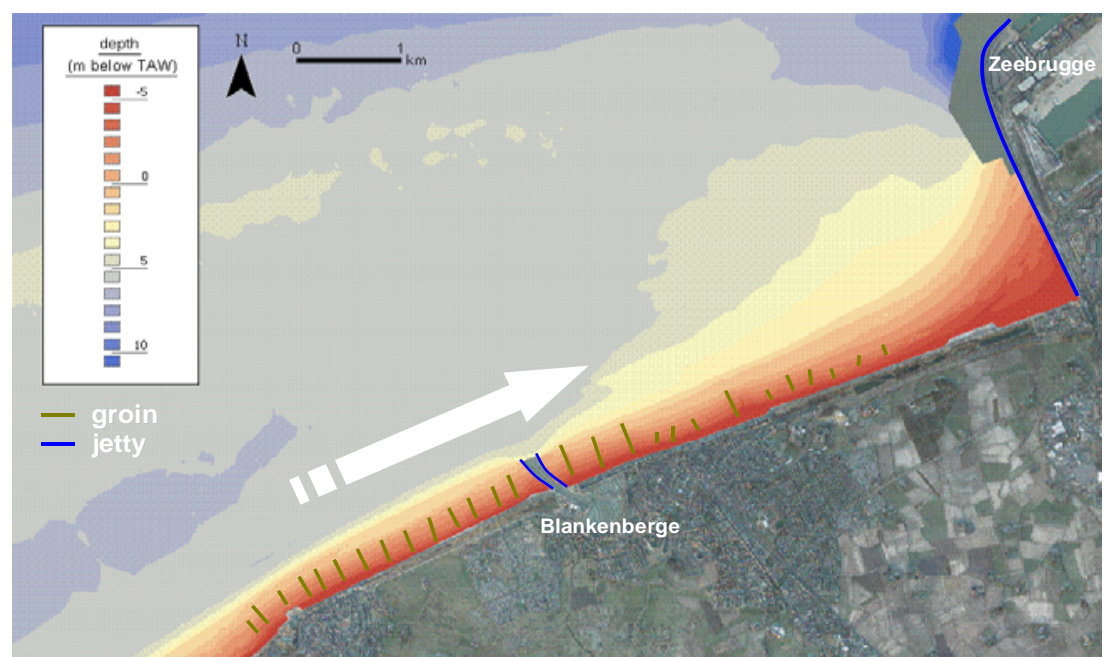

Fig. 3. Bathymetry of the study area, location of groins (green) and of the jetties (blue) of the harbor of Blankenberge and the West breakwater of the harbor of Zeebrugge (Top right). The white arrow indicates the direction of longshore transport. The morphological analysis is performed in the part of the coast between Blankenberge and the harbor of Zeebrugge. 
Figure 3 shows the location of both harbors and the numerous groins. The arrow indicates the dominant direction of the littoral drift.

Data are interpolated to a rectangular $5 \mathrm{mx} 5 \mathrm{~m}$ grid. Once all bathymetric grids are ready for every year a comparison of the datasets is carried out. Areas for which no overlap between datasets is found are left out of the analysis. As a final result, positive differences are interpreted as accumulation and negative quantities as erosion.

For each pixel ( $5 \mathrm{~m}$ x $5 \mathrm{~m})$ the erosion/sedimentation trend was calculated using linear regression. The volumes of sediment were calculated above an arbitrary ground level. This result was used to delineate areas with differing morphological trends. Due to the lack of a continuous dataset for the complete area, the analysis is performed separately for the foreshore-years 1999, 2000, 2003 and 2007- and for the beach -years, 2000, 2001, 2006, 2007 and 2008-. For the analysis in deeper areas, data from 1995, 1997, 1999, 2002 and 2003 was used. Care was taken to account for anthropogenic supply of sediment to the system, namely beach nourishments and disposal of dredged material in the vicinity of Blankenberge, Southwest of the Zeebrugge harbor. Figure 4 shows the different zones indentified in the study area.

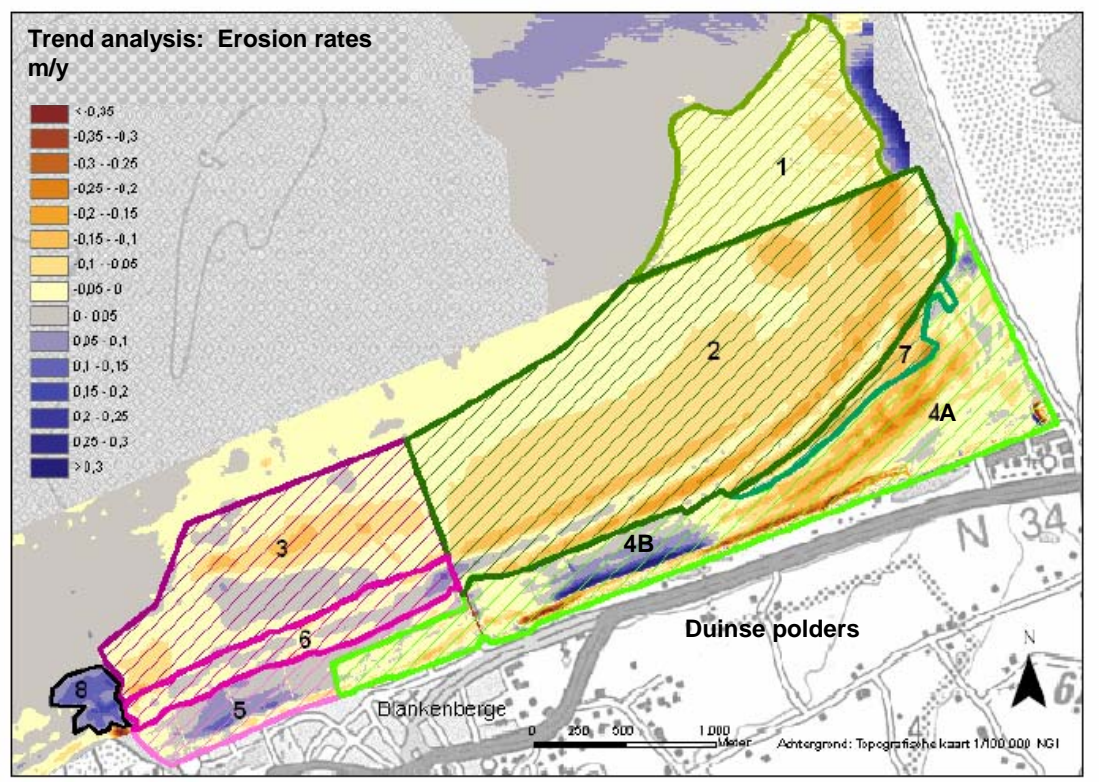

Fig. 4. Study area divided in areas depending on type and data availability: Zone 1: deep area; Zone 2: foreshore east; Zone 3: foreshore West deeper than -2m; Zone 4: beach East; Zone 5: beach West; Zone 6: foreshore West shallower than -2m; Zone 7: area without overlap; zone 8: harbor foreshore. 
24/07/1998 6/12/1999 19/04/2001 1/09/2002 14/01/2004 28/05/2005 10/10/2006 22/02/2008
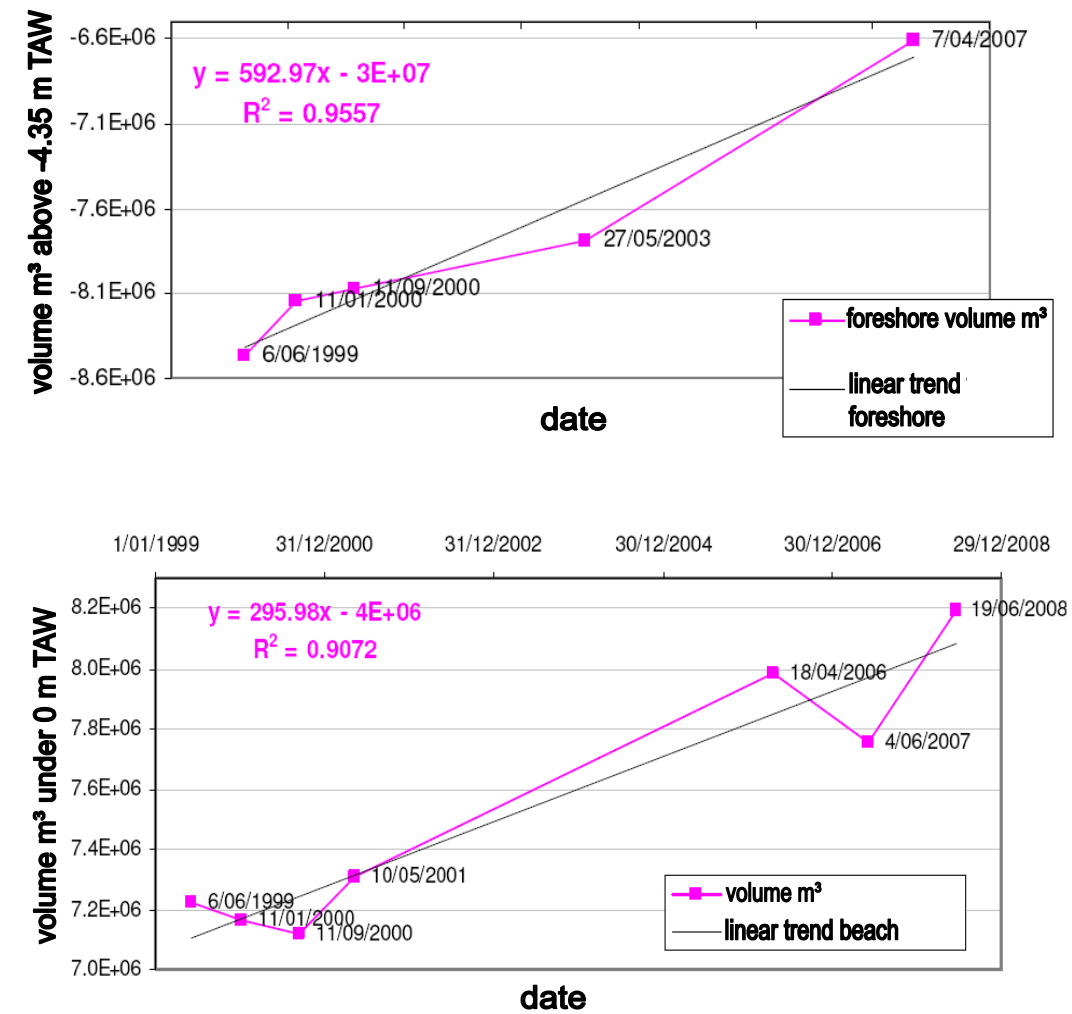

Fig. 5. Results of Linear Regression for Zone 2 (above) and zone 4 (below)

The quantification of volumes eroded or accreting in the time period considered is done by zone: erosive areas are evaluated separately. Also the difference in years or dates for the different datasets is taken into account. The evaluation is also done separately for the foreshore, the beach itself and the rest of, generally deeper, zones. Unfortunately, no complete overlap between the different datasets was achieved in some cases. This fact can be observed at area 5, near the dam of Zeebrugge, at the $1.5 \mathrm{~m}$ TAW line. The total volume per zone was calculated after an averaged depth multiplying the total area of the site. For beach volumes in the years 2006, 2007 and 2008 a volume of $250,000 \mathrm{~m}^{3}$ is added to compensate for the excavation in 2006. The average erosion / sedimentation each year is estimated by the linear trend in the volume calculation. 


\section{Results of the morphological analysis}

Results of this analysis are shown in Figure 4. For clarity, different areas in the figure are identified by numbers in order to easily connect them with the explanation that follows.

The overall trend clearly indicates accumulation which is presumed to be caused by the blockage of the littoral drift, which upstream harbor of Zeebrugge has a direction from (south)west to (north)east. On the beach, next to this harbor, a layer of sand of $0.85 \mathrm{~m}$ over an area of 250,000 $\mathrm{m}^{2}$ was extracted from the system in 2006. This area presents no significant erosion after the trend analysis, which indicates that the sediment extracted has being progressively replaced by the system. According to the same results, some areas subject to erosion can also be identified. In most of the cases this can be explained by anthropogenic activities, namely (zones indentified as in Figure 4):

Zone 4:

- 4A. Directly adjacent to the western breakwater of Zeebrugge remains a small area of local erosion explained by regular small-scale excavations carried out to counterbalance the formation of ridges. In this area there is an aeolian contribution to the sediment budget estimated to be around $16000 \mathrm{~m}^{3}$.

- 4B. Westwards the area of main accumulation there is a small area that locally presents a strong erosive character. This is due to the nourishment of the beach at Duinse Polders with 486,300 $\mathrm{m}^{3}$ of sand in 1998-1999 (The nourishment was done for safety reasons since the dunes in the area presented only a limited development insufficient to protect the area from flooding during severe storm conditions).

Zones 5 and 6: Downstream erosion due to the response of the system to the presence of the harbor of Blankenberge.

Zone 8: The negative balance shown by the analysis in this area is due to the constant dredging needed to eliminate the excess of sediment that accumulates in the harbor of Blankenberge.

The results provide an estimation of sediment volume transported per year. Table 1 summarizes the volumes calculated at four different zones of the study area. 
Table 1. Erosion-accumulation trends calculated at the Blankenberge area, Southwest of the Harbor of Zeebrugge

\begin{tabular}{lccc}
\hline & $\begin{array}{c}\text { Best estimate, } \\
\text { m3/year }\end{array}$ & $\begin{array}{c}\text { Standard deviation, } \\
\text { m3/year }\end{array}$ & Remark \\
\hline $\begin{array}{l}\text { Accumulation immediately } \\
\text { west of western breakwater }\end{array}$ & +370000 & 30000 & $\mathrm{R}^{2}<0.5$ \\
$\begin{array}{l}\text { Erosion beach area } \\
\text { Blankenberge }\end{array}$ & -5000 & 5000 & \\
$\begin{array}{l}\text { Accumulation dumping place } \\
\text { foreshore of Blankenberge }\end{array}$ & +35000 & 1000 & \\
$\begin{array}{l}\text { Erosion in front of } \\
\text { Blankenberge marina }\end{array}$ & -1000 & 5000 & $\mathrm{R}^{2}<0.5$ \\
\hline
\end{tabular}

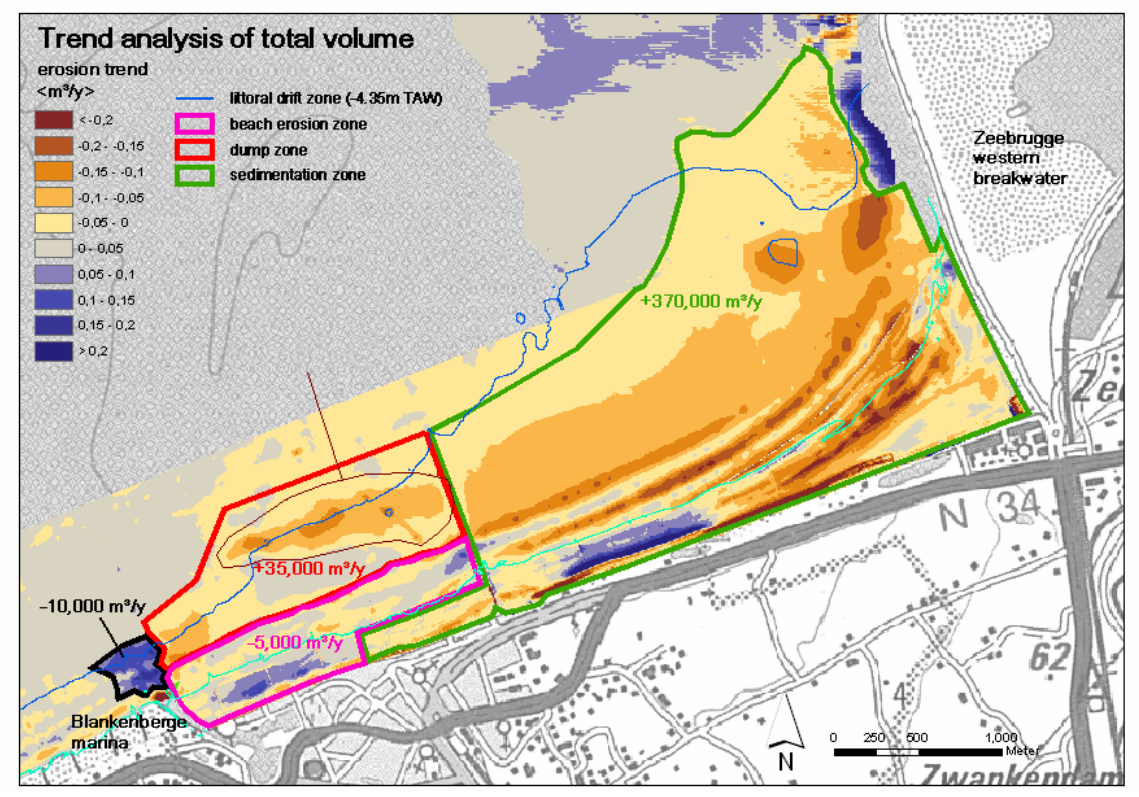

Fig. 6. Result of morphological trend analysis to delineate the accumulation area west of the western breakwater, caused by blockage of the littoral drift. 
Figure 6 gives an overview of volumes eroded (in blue) and accreted (brown) in the study area. The total estimate of the littoral drift based on the measured volumetric trends and assuming that no sediment is brought into the system from offshore areas is of $395 \times 10^{3} \pm 35 \times 10^{3} \mathrm{~m}^{3} /$ year.

\section{Numerical modeling of the longshore sediment transport}

A simple, one-dimensional model was set up representing a simplified version of the study area. The goal is to reproduce the results found in the trend analysis and to get information about the mechanisms driving the distribution of sediment in the area. The commercial LITDRIFT software (MIKE by DHI 2008) was chosen for this purpose. This model calculates longshore transport across a single profile, therefore, only one typical coastal profile was used to represent the whole coast. This approximation was found appropriated because of the uniformity of the slope along this stretch of the rectilinear Belgian coast and because the model does not take into account the presence of structures. The model domain extends until a water depth of -8m TAW considered well beyond the end of the active profile. Both seawards and East boundary are set as closed.

In Figure 7, results from the numerical model LITDRIFT are shown. The volumes of sediment transported over the beach profile are shown, indicating that most of the transport occurs between the $-2 \mathrm{~m}$ and the $+4.5 \mathrm{~m}$ TAW.

To obtain these results, the system was considered being fully driven by breaking waves only. This means that the model does not account for wind or tidal forcing. The wave climate was determined by hindcasting a 10 year period with a SWAN model with boundary conditions from deep water wave buoy and wind data (Verwaest et al. 2008). Results of the morphological trend analysis are used to calibrate the model. After calibration, a presumed constant bed roughness parameter and a uniform averaged grain size of $0.22 \mathrm{~mm}$ based on a limited number of sediment samples resulted in a littoral drift equal to the empirical value mentioned. More interestingly, from the results of the calibrated model it was possible to quantify the ratio of the gross total longshore transport for both directions, as well as to have some indication on the cross-shore distribution of longshore transport. In casu the gross transport from west to east seems to be a factor 3.5 larger than the gross transport from east to west, and in cross-section the longshore transport takes place in a height zone between the average high water mark and $2 \mathrm{~m}$ below the lowest low water mark with strong variations in the profile caused by the barred beach geometry. 


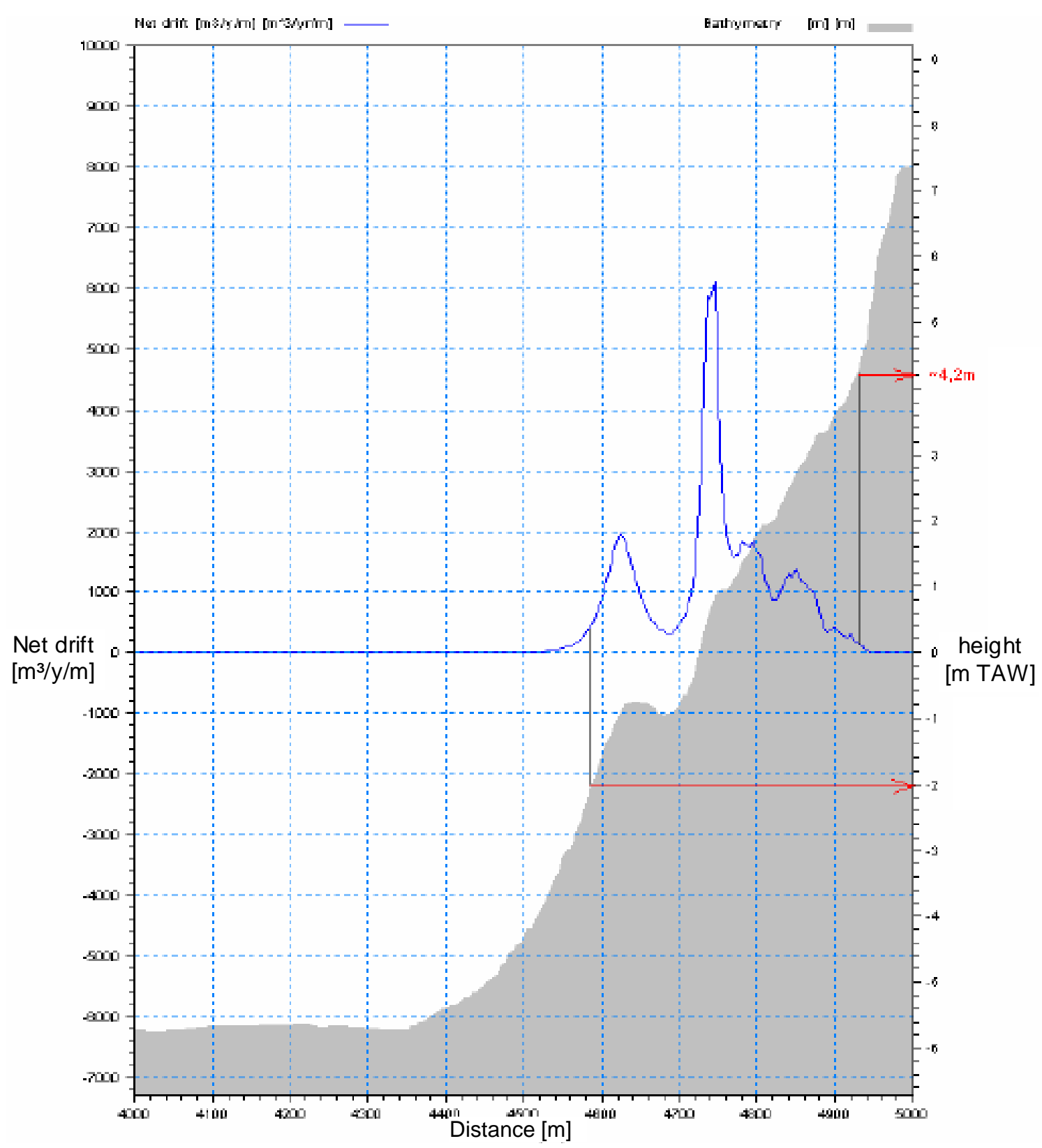

Fig. 7. LITDRIFT results of net littoral drift in function of the bathymetry for the Blankenberge area. 
Table 2. Net and gross longshore transport depending on the direction considered.

\begin{tabular}{lccc}
\hline $\begin{array}{c}\text { Net drift } \\
\mathbf{m}^{3} / \text { year }\end{array}$ & $\begin{array}{c}\text { Gross longshore transport } \\
\mathbf{m}^{\mathbf{3}} \text { year }\end{array}$ & $\begin{array}{c}\text { Longshore transport } \\
\text { West to East, } \mathbf{m}^{\mathbf{3}} \text { year }\end{array}$ & $\begin{array}{c}\text { Longshore transport } \\
\text { West to East, } \mathbf{m}^{\mathbf{3}} \text { /year }\end{array}$ \\
\hline 395000 & 685000 & 540000 & 145000 \\
\hline
\end{tabular}

Table 2 shows net and gross volume transported in different directions during the time period object of this study after results of the numerical modeling with LITDRIFT.

\section{Discussion and conclusions}

A series of morphological trend analysis based on 10 years of bathymetric data and 1D LITDRIFT numerical simulations have been performed in order to estimate the littoral drift at the Blankenberge area. The area is strongly influenced by the harbor of Zeebrugge, presumed to block longshore sediment transport producing a fast accumulation of sediment upstream, next to its westernmost breakwater, more than 3 $\mathrm{km}$ long.

The total net drift estimated after the morphological trend analysis is $395000 \mathrm{~m}^{3} / \mathrm{y}$. This analysis includes data obtained at water depths of up to $-4.5 \mathrm{~m}$ TAW and it is based on the assumption that all the sediment in the system is transported by littoral drift. The results of the $1 \mathrm{D}$ numerical modeling, obtained under the same assumption and calibrated after the results of the morphological trends previously assessed, indicate that most of the longshore transport occurs between the +4.35 TAW and the $-2 \mathrm{~m}$ TAW line.

At the moment, there are no measurements allowing for a direct validation of this results which are obtained under a number of assumptions some of which should be further investigated. This is the case of the uncertainty about the actually active sediment transport zone, active profile or closure depth of wave driven transport. More importantly, the assumption of no sediment flow across the offshore and the eastern boundary might be correct for a study aiming at the evaluation of the sediment transported by littoral drift but in order to explain the sediment dynamics in the study area, other mechanisms should be taken into account for the interpretation of the results of the morphological trend analysis.

Above the $+4.2 \mathrm{~m}$ TAW line, sediment transport is associated to aeolian processes transporting sand from the beach berm to the feet of the dunes but there are also other elements, such as the possible contribution of storms, and swash during spring tides that needs to be taken into account. 
Below the $-2 m$ line other processes than littoral drift should be examined in order to explain the sediment dynamics in the area. For this purpose, a 2D modeling approach allowing for the investigation of the contribution of the cross-shore transport is currently under investigation.

\section{Acknowledgements}

This research was co-financed by the Coastal Division of the Maritime and Coastal Services of the Flemish government.

\section{References}

Kobayashi, N., Agarwal, A. and Johnson, B. 2007. Longshore current and sediment transport on beaches. Journal of Waterway, Port, Coastal and Ocean Engineering, 133(4), 296-304.

Ruessink, B. G., Miles, J. R., Feddersen, F., Guza, R. T., and Elgar, S., 2001. Modeling the alongshore current on barred beaches. J. Geophys. Res., 106(C10), $22,451-22,463$

Verwaest, T., Doorme, S., Verelst, K. and Trouw, K. 2008. "The wave climate in the Belgian coastal zone.” LITTORAL 2008. A Changing Coast: Challenge for the Environmental Policies. Proceedings 9th International Conference, [CDROM]. pp. 1-8. 